\title{
Aspectos Gerais da Aplicação de Sistemas de Informação na Agropecuária
}

\author{
Claudio José de ALMEIDA ${ }^{1}$, Daniel Baltazar CHAVES ${ }^{1}$, Ricardo Baltazar CHAVES ${ }^{1}$, \\ Sandro Campos GRANATO ${ }^{1}$, Flávio Campos CARELLI ${ }^{2}$, Tito Livio Gomes OSÓRIO ${ }^{2}$ \\ Marcelo GENESTRA ${ }^{2 *}$ \\ ${ }^{1}$ Bacharéis em Sistemas de Informação / UniFOA / \\ Fundação Oswaldo Aranha. Centro Universitário de Volta Redonda. Av. Paulo Erlei \\ Alves Abrantes, 1325 - Três Poços - Volta Redonda/RJ \\ ${ }^{2}$ Docentes do Curso de Graduação em \\ Sistemas de Informação / UniFOA / Fundação Oswaldo Aranha. Centro Universitário de \\ Volta Redonda Av. Paulo Erlei Alves Abrantes, 1325 - Três Poços - Volta Redonda/RJ \\ marcelo.genestra@foa.org.br
}

\begin{abstract}
Resumo
Um dos aspectos mais importantes das diferentes criações é a alimentação correta de forma a se obter um desenvolvimento adequado dos animais. Precocidade, ganho de peso, aumento na produção de leite, de ovos entre outros, são necessidade para os produtores que se dedicam à pecuária. Para alimentação dos animais de produção, é preciso fornecer rações concentradas; que são fontes de proteínas e energia necessárias ao seu bom desempenho. Entretanto, as rações são onerosas e isto pode levar os produtores a abandonarem seus projetos de criação. O preparo de rações balanceadas pode ser uma solução para este problema. Os Sistemas de Informação (SI) podem ser desenvolvidos para possibilitar aos produtores o preparo destas rações aproveitando alimentos de sua propriedade reduzindo os custos de produção e como conseqüência, aumentando seus lucros.

Palavras-chave: Sistema de Informação, "software”, produção, ração.
\end{abstract}

\begin{abstract}
One of the most important aspects in the different creations is the correct feeding of form if to get an adequate development of animals. Precocity, profit of weight, increase in the egg, milk production among other, are necessity of producers that if dedicated to the cattle one. For feeding of the production animals, it is necessary to supply intent rations, that they are necessary protein source and energy to its good performance. Rations are onerous and this can take the producers to abandon its project of creation the preparation of balance rations can be a solution of this problem. It self food of this property can be developed to make possible to the producer the preparation of this ration using to advantage reducing the production costs and as consequence, increase its profits.
\end{abstract}

Key words: Information system, software, production, ration.

\section{INTRODUÇÃO}

Na última década tem havido um desequilíbrio entre o aumento de insumos e o valor final de produtos pecuários. Por este motivo, produtores têm sido levados a abandonarem as suas atividades no campo, o que tem reflexos diretos na economia do País. Animais de alta produtividade, como reprodutores e matrizes, animais de corte e de produção leiteira e animais de trabalho e esporte necessitam de suplementação alimentar, composta, entre outros, de rações balanceadas formadas por elementos que contêm suplementos alimentares, principalmente de proteínas e minerais. Estas rações são produzidas buscando-se um equilíbrio complexo de diversos nutrientes, o que torna pouco viável a sua preparação, pela maioria dos produtores, que 
precisariam de um conhecimento especializado para tal [1].

Outro aspecto importante de ser observado é que, dependendo da época do ano e da região, há diferentes produtos que podem ser aproveitados no preparo da ração; o que torna menos dispendiosa sua utilização. Porém, como estes alimentos têm diferentes composições, o balanceamento adequado dos mesmos torna difícil sua utilização em diferentes formulações. Baseado nesse problema surge a proposta da utilização de sistemas de informação, para auxiliar os produtores no preparo de rações balanceadas, usando os componentes produzidos na própria fazenda, ou comprados nas lojas especializadas. Este sistema possibilitará um balanceamento correto dos nutrientes, produzindo uma ração de qualidade, pois os cálculos necessários para que isso ocorra serão muito mais precisos [1]..

Esta prática poderá aferir benefícios diretos, cujos efeitos serão vistos a curtos e médios prazos, tais como:

1 - Financeiro: quando for necessária a utilização de elementos para a fabricação da ração, e tais elementos não forem originados da própria sede do fabricante da ração, eles serão adquiridos em quantidades exatas, evitando-se, assim, gastos desnecessários.

2 - Reciclagem: a utilização de Sistema de Informação (SI) na fabricação da ração acarretará numa reciclagem de vários elementos da própria sede do fabricante, antes desperdiçados.

3 - Nutrição: as rações serão produzidas levando em consideração a necessidade de cada espécie de animal, e, também, utilizando elementos de procedência conhecida, teremos animais mais bem nutridos, menos sujeitos a doenças e parasitas.

O desenvolvimento da genética na pecuária de carne, leite ou lã, tem atrelado a si o conhecimento dos aspectos relacionados com a alimentação animal. Estas informações têm um emprego melhor quando organizadas e processadas de forma adequada, permitindo um retorno das mesmas de maneira mais proveitosa ao produtor. A análise, a implementação e a operação de um SI dependem de diversos fatores. Assim, num projeto de SI precisa-se avaliar não só a sua viabilidade científica e tecnológica, como também a viabilidade econômica, pela relação custos benefícios, além de uma análise dos pontos positivos e aspectos negativos do seu desenvolvimento e uso.

Ração é o termo comumente empregado para designar a alimentação diária de um animal. Ela pode conter diversos elementos, tais como: a) volumosos: são os capins e fenos; b) concentrados: são as misturas de nutrientes e suplementos alimentares, preparados para fornecer altas concentrações de proteínas e elementos minerais (macro e micro elementos).

O conhecimento da composição necessária aos diferentes alimentos, permite a formulação de rações específicas para: o crescimento de filhotes, a produção de leite ou carne, a reposição dos elementos necessários para animais de trabalho ou de competição, etc. A utilização de um SI, desenvolvido especificamente para esta área, capacita o produtor a preparar rações que atendam às necessidades de animais das várias categorias descritas, utilizando os alimentos disponíveis em sua propriedade, reduzindo consideravelmente o custo com a aquisição dos elementos necessários para a complementação da alimentação dos animais, o que torna mais viável, tanto para o pequeno, quanto para o grande produtor, o desenvolvimento e a melhoria do desempenho de suas criações [1]..

\section{SISTEMAS DE INFORMAÇÃO}

As transformações por que passam todas as atividades dos diferentes seguimentos sociais, políticos e econômicos da humanidade de uma forma geral, nos leva a afirmar que estamos vivendo, hoje, em uma economia que tem como base fundamental a informação. Note-se que a informação representa um elemento de valor, a ser agregado aos credos das diferentes atividades, perfazendo áreas de comércio de informações, tal como o comércio outrora existente que negociava bens e serviços.

O uso dos sistemas computadorizados como meio para criar, armazenar e transferir informações é uma realidade que não deixa dúvidas, e um exemplo claro disso é a quantidade de sistemas de informação, gerando informações em todos os níveis nas empresas, auxiliando, como ferramenta imprescindível, aos investidores, em todas as áreas e atividades, a tomarem decisões, o mais das vezes milionárias, sem falar no volume de capital que gira eletronicamente ao redor do mundo, em transações comerciais, que utilizam a Tecnologia de Informação de uma forma mais abrangente [2]..

O propósito de um projeto de sistemas é o de elaborar o detalhamento das necessidades do sistema novo ou modificado. As suas dimensões lógicas referem-se ao modo como os vários componentes do SI funcionarão quando estiverem juntos. O projeto lógico inclui a especificação de dados para saídas e entradas, processamento, arquivos, banco de dados, telecomunicações, procedimento, pessoal e equipe e do projeto, além dos projetos de segurança e controle de operação.

Como qualquer tarefa ou atividade, o desenvolvimento de um sistema de informação deve ser corretamente planejado, dividido em etapas perfeitamente definidas, que serão coordenadas e controladas durante todo processo de execução. Ditas etapas constituem o "ciclo de vida de um sistema de informação" e incluem: 
$\checkmark$ A investigação do sistema - para obter um claro entendimento do problema;

$\checkmark$ A análise do sistema - que define o que o sistema precisa fazer para resolver o problema;

$\checkmark$ O projeto de sistema - que determina exatamente como o sistema funcionará para atender às necessidades;

$\checkmark$ A implementação - que é a criação ou a aquisição de vários componentes definidos no estágio de projeto;

$\checkmark$ A manutenção - que pode ser dividida em corretiva e preventiva e tem como objetivo fazer os necessários ajustes para o seu perfeito funcionamento

$\checkmark$ A validação - processo no qual o sistema é aceito e validados os seus objetivos; e

$\checkmark$ Operação - que consiste na sua utilização pelo usuário.

Independente do esforço particular de desenvolvimento de sistemas, o processo deve definir um sistema com objetivos específicos de desempenho e de custos. O sucesso ou fracasso do esforço do desenvolvimento será comparado com esses objetivos.

$\checkmark$ Objetivo de desempenho - A performance almejada para um sistema pode ser mensurada pelos seus objetivos de desempenho:

a) Qualidade ou utilidade de sua saída;

b) Qualidade ou utilidade no formato de sua saída;

c) Velocidade na qual a saída é gerada.

Em alguns casos, o alcance dos objetivos de desempenho pode ser facilmente medido. No entanto, o alcance dos objetivos de desempenho é mais difícil de verificar a curto prazo, pois eles estão atrelados à meta das empresas.

$\checkmark$ Objetivo de Custo - Os benefícios de se alcançar as metas de desempenho devem ser equilibrados com todos os custos associados ao sistema, e podem ser listados:

a) Custos de desenvolvimento;

b) Custos relacionados à exclusividade do sistema;

c) Investimento fixo em hardware e equipamentos fins;

d) Custos operacionais contínuos.
A viabilidade do desenvolvimento e da operação de um SI inclui uma abordagem que lista os custos e os benefícios de cada sistema proposto. Uma vez expresso em termos monetários, todos os custos são comparados com os benefícios. Uma das desvantagens da análise de custo benefício é a dificuldade em determinar valores monetários para todos os benefícios. Por esse motivo se utiliza o sistema de avaliação de pontos para determinar os benefícios de um SI. Cada fator da avaliação corresponde a um peso, em pontos percentuais, com base na importância.

$\mathrm{O}$ impacto de um sistema sobre a capacidade de uma organização em atender às suas metas determina o real valor daquele sistema para a organização. Dessa maneira, é de se esperar que os sistemas de informação possam ser aplicados nas várias atividades rurais, tais como na confecção de implementos e suplementos alimentares, e que o seu uso acarrete em considerável redução dos custos com implementos alimentares para animais de alta produção.

\section{Ração}

O custo da alimentação representa de 50 a $65 \%$ do custo da produção do leite, assim, qualquer economia na obtenção da ração tem grande reflexo sobre o sucesso da exploração leiteira. Justamente pela representatividade deste custo é que a confecção da ração torna mais complicada a escolha dos insumos, pois muitos nutrientes considerados excelentes precisam ser postos de lado por causa do preço, sendo substituído por outros mais baratos [3].

O elevado custo com os nutrientes faz com que seja, sempre, interessante a utilização da maior quantidade possível de alimentos produzidos na fazenda, em detrimento da compra dos concentrados indispensáveis, no balanceamento das rações. $\mathrm{O}$ criador não se deve preocupar demais com o preço da tonelada de ração, mas sim, com o custo das unidades de proteína digestível e de nutrientes totais, isto é, com o custo das partes realmente úteis do alimento ou da ração. Assim, conhecidos os preços e as percentagens de proteínas e de nutrientes digestíveis totais de dois alimentos da mesma categoria, é fácil a determinação do qual será mais conveniente, sob o aspecto econômico, pelo custo do quilo de proteínas digestíveis) (P.D.) e de nutrientes digestíveis totais (N.D.T.).

Há diversos métodos para a determinação do custo dos nutrientes e o criador deve estar atento a variações de disponibilidade e de preço dos alimentos, geralmente em caráter temporário, para poder balancear a ração de modo mais barato e fácil, mantendo o mesmo rendimento. Os silos, as medas de feno e as capineiras, bem como o uso de cevada obtida de cervejarias, são ótimos meios de obtenção de alimentação mais econômica, mas, as vezes, torna-se melhor colher e vender o milho, e não fazer silagem, e optar por comprar concentrados. 


\section{O sistema de informações no campo}

A evolução científica e tecnológica tem acarretado, entre outras coisas, um grande número de descobertas em todas as áreas do conhecimento humano, e, ainda, graças a esse desenvolvimento tecnológico, tais descobertas são divulgadas com facilidade para todo o mundo, surgindo a necessidade de que essa grande quantidade de informações tenham de ser armazenadas, organizadas e divulgadas de forma correta, para que se possa aproveitá-las com mais eficiência.

$\mathrm{Na}$ pecuária, assim como nas diferentes atividades, observam-se as conseqüências desta evolução científica. Assim sendo, o aprimoramento da qualidade na criação de gado de corte, com o aumento da fertilidade, a precocidade reprodutiva, o aumento de ganho de peso rapidamente, são frutos de pesquisas realizadas no mundo inteiro e a TI sempre está presente como parte desse desenvolvimento [3].

As criações de gado leiteiro têm todas as características acima citadas e mais a necessidade do melhoramento na aptidão leiteira, utilizando-se de técnicas de fertilização em laboratórios, como forma de melhoria genética do rebanho. Grandes e médios produtores têm melhorado consideravelmente a genética de seus rebanhos leiteiros, com reflexos diretos na produção diária de derivados do leite.

A equinocultura, caprinocultura, ovinocultura, avicultura, piscicultura, e mais recentemente, a criação de avestruzes e animais silvestres, enfim todas estas criações são desenvolvidas a partir de um melhoramento genético, e para tal, a alimentação é um item de fundamental importância [4].

Porém, é certo também que os animais criados somente a pasto, não atingem níveis de desenvolvimento daqueles tratados com suplementos e concentrados alimentares. Assim como na genética, as pesquisas sobre alimentação, seus componentes e emprego, têm sido foco de estudos, e novas descobertas (informações) são feitas diariamente. A manipulação destas informações torna-se difícil por causa de sua diversidade e complexidade, obrigando que os criadores estejam atentos às novas descobertas e que o setor de industrialização de alimentos concentrados se adaptem a essa nova realidade e disponibilizem os suplementos alimentares necessários ao desenvolvimento dos rebanhos em geral.

Porém, o que se tem visto é que tais suplementos são colocados no mercado a preços exorbitantes, fazendo com que o pequeno produtor não tenha acesso a esses produtos e, conseqüentemente, não consiga a melhoria do rebanho a ponto de se manter na disputa do mercado.

Conforme já mostrado anteriormente, a ração balanceada é um conjunto de alimentos que satisfaz as necessidades diárias de um animal, possuindo todos os nutrientes necessários, nas quantidades e proporções devidas. Ela é preparada para um grupo de animais com necessidades semelhantes [4].

\section{Sendo assim, u m SI poderá ajudar a} solucionar esse processo de exclusão do pequeno produtor, pois, a utilização de variados alimentos, nas quantidades corretas, e que estão disponíveis na propriedade poderá substituir o uso de concentrados industrializados, fazendo com que, gradativamente este produtor alcance a melhora da performance de seu rebanho. Mesmo que as misturas naturais requeiram um conhecimento especializado, existem órgãos governamentais, tais como a EMBRAPA (Empresa Brasileira de Pesquisa Agro-Pecuária) que fornecem acessoria aos produtores, orientando-os na composição da suplementação alimentar necessária à melhoria do rebanho [4].

Todavia, é necessário que o produtor esteja atento a alguns fatos importantes, pois, dependendo da região, os alimentos disponíveis para o preparo das rações são diferentes, o que pode onerar ou baratear o custo final da mesma. Se os alimentos mudam, o equilíbrio precisa ser refeito. Estas informações (conhecimentos) podem ser organizadas em um sistema, que permita um acesso preciso, completo e rápido, o mesmo acontecendo com as atualizações, frutos dos resultados de novas pesquisas, que tem como conseqüência direta a freqüente reformulação dos elementos. Ai, novamente estará presente o SI, trabalhando esta atualização, classificando novos alimentos e reformulando as misturas, para obtenção de resultados cada vez melhores [5].

O desenvolvimento de um SI para aplicação nesta área deverá contar com uma equipe multidisciplinar, pois, além dos profissionais cujo conhecimento é específico para a área dos SI, deverão participar outros profissionais de diferentes áreas do conhecimento, tais como: pecuária, biologia, genética, agronomia e nutrição animal, etc. Este trabalho deverá contar, também, com a participação do produtor que poderá dar informações de grande valia, fruto da sua experiência do dia-a-dia no manejo de rebanhos e no plantio correto de produtos agrícolas que irão compor o suplemento alimentar.

Se dentre os motivos que levam a iniciar um SI, encontra-se o de resolver problemas já existentes; aproveitar oportunidades para obter vantagens competitivas; enfrentar a concorrência, e, ainda, como visto no capítulo 2,"o custo da ração representa $50 \%$ a $60 \%$ do custo de produção de leite", nada melhor do que fazer uso de tais recursos na tentativa de reduzir estes custos, oferecendo oportunidades iguais aos diferentes produtores, de forma que tenham vantagens competitivas e que possam sobreviver num mercado cada vez mais exigente [5].

O Ciclo de Vida do Desenvolvimento do Sistema (CVDS) se dará com o acompanhamento constante das pesquisas na área da pecuária. Suas fases: avaliação, análise, projeto, implementação e manutenção, deverão acontecer sob o acompanhamento 
da equipe assistida pelos técnicos, como visto anteriormente. Todavia faz-se necessário que se avalie corretamente o uso dos SI, pois existem algumas desvantagens que podem inviabilizar o seu desenvolvimento, o que irá requerer uma avaliação criteriosa da relação custo $\mathrm{x}$ benefício, na hora de decidir sobre o seu desenvolvimento e utilização.

Outros fatos a serem levados em consideração é que os usuários podem estar distribuídos em locais longínquos, o que dificultaria "a revisão dos produtos intermediários". Além disto, se os especialistas não conhecerem bem as características destas regiões distantes, e os tipos de criações da propriedade, "as necessidades dos usuários não declaradas inicialmente poderão não ser atendidas”, já que "não há dois alimentos absolutamente iguais, e que, na prática, na alimentação se faz pela substituição recíproca entre alimentos de propriedade gerais semelhantes, de acordo com os preços mais convenientes" [6]

O desenvolvimento dos softwares deverá ter o enfoque principal na formulação de rações concentradas, pois, como visto, estes são os alimentos que elevam o custo da produção e, no entanto, são os alimentos de alta concentração de nutrientes energéticos.

O Brasil é o país considerado como o celeiro da humanidade. O maior rebanho do mundo (segundo maior exportador); maior produtor de aves, um dos maiores de grãos. Por todo este potencial, pode-se assegurar que no campo haverá espaço para o desenvolvimento de SI que, como se observa, poderá melhorar a qualidade e produtividade de seus rebanhos $[4,6]$.

Portanto, o custo-benefício da implementação de SI será compensatório para todos, pois, por ser um mercado fértil, o volume poderá ser grande, barateando a produção dos Sistemas de Informação. Por outro lado, os produtores poderão preparar alimentos de boa qualidade a preços mais acessíveis, melhorando a qualidade e a produtividade de seus rebanhos .

A implementação destes sistemas não seria difícil; o cuidado, no entanto, é com a consideração das características de cada criação e a disponibilidade dos elementos nas diversas regiões, podendo, desta forma promover a redução no custo de produção, já que as rações concentradas são os elementos mais caros na linha de produção, com reais benefícios para a melhoria da qualidade do rebanho e da produção, promovendo o desenvolvimento da atividade agro-pecuária.

\section{BIBLIOGRAFIA}

[1].BATISTTON, W.C. Gado leiteiro. Campinas: ICEA, 1981. 404p.

[2].CERVO, A.L.; BERVIAN, P.A.. Metodologia científica. 5 ed. São Paulo: Prentice Hall (2002). $242 \mathrm{p}$.

[3].GONÇALVEZ, R.L. Alimentação correta. Horse Business, 54 (1999).

[4].JARDIM, W.R. Criação de caprinos. 11 ed. São Paulo: Nobel, (1987). 239p.

[5].STAIN, R.M.; WOLDS, G.W.R. Princípios de SI. 4 ed. LTC, (1999). 496p.

[6].VASCONCELLOS, P.M.B.. Guia prático para o fazendeiro. 2 ed. São Paulo: Nobel. (1982). $405 p$. 